\title{
Mental health, duration of unemployment, and coping strategy: a cross-sectional study of unemployed migrant workers in eastern china during the economic crisis
}

Li Chen ${ }^{1,2}$, Wenhu Li ${ }^{2}$, Jincai He${ }^{1}$, Lanhua Wu', Zheng Yan $^{3}$ and Wenjie Tang ${ }^{1 *}$

\begin{abstract}
Background: 20 million migrant workers in China lost their jobs during the economic crisis of 2008. Both urban migration and unemployment have long been documented to be associated with vulnerability to mental problems. This study aims to examine the mental health of unemployed migrant workers in Eastern China and its relation to duration of unemployment and coping strategy during the recent economic crisis.

Methods: The data were collected through interview-based survey with a sample of 210 unemployed migrant workers in Zhejiang Province of China from 2008 to 2009. Symptom Checklist-90-Revised, Coping Strategies Questionnaire, and seven short demographic questions were used.
\end{abstract}

Results: The majority of the unemployed migrant workers were found to be young male manufacturing industry workers with short-term unemployment and a relatively low education level. Nearly $50 \%$ of unemployed migrant workers were classified as mentally unhealthy and the most frequently reported symptom was depression. Compared with the adult norm of 1986, 2003, and 2007 in China, unemployed migrants had more mental problems. Long-term unemployed migrant workers had more psychiatric symptoms than the short-term unemployed workers and employed migrant workers. Unemployed migrant workers with immature coping strategies expressed significantly more psychiatric symptoms than those with mixed and mature coping strategies. Duration of unemployment and two coping strategies, problem-solving and self-blaming, predicted the mental problems of unemployed migrant workers.

Conclusions: The results indicated that mental health status of unemployed migrant workers in Eastern China was poorer than the national adult norm. More psychiatric symptoms are evidenced among unemployed migrant workers who lost their jobs for a long term and who had immature coping strategies. These findings can be used for prevention and intervention of mental illness among unemployed migrant workers.

Keywords: Mental health, Duration of unemployment, Coping strategy, Unemployed migrant workers, Economic crisis

\footnotetext{
*Correspondence: tang13606777777@yahoo.com.cn

'Department of Psychology, School of Environmental Science and Public Health, Wenzhou Medical College, Wenzhou, China

Full list of author information is available at the end of the article
} 


\section{Background}

The worldwide economic crisis of 2008 resulted in massive unemployment across the world. In June 2009, for example, approximately 45 million (8.3\%) people living in the member countries of Organisation for Economic Co-operation and Development (OECD) were unemployed and estimated unemployment rates in underdeveloped countries were even as high as 80-90\% [1].

Unemployed people generally experience three major types of distress. The first is financial distress. They have to face financial ruin, and many begin to lose their lifetime savings and even their homes [2]. The second is physical health. Medical symptoms such as diabetes, hypertension, and coronary heart disease are associated with unemployment [3-5]. The third is mental health. Poor mental health is common among the unemployed $[6,7]$ and unemployment is associated with higher levels of depression [8,9], suicide [10] and anxiety [11].

Published studies on the relationship between unemployment and mental health have extensively focused on developed countries in the West [7-10] and unemployed urban residences with labor insurance (e.g. nurses, white-collar employees, and stable workers) [12-14]. These studies not only have significantly advanced current knowledge concerning the mental health of unemployed urban individuals in the Western countries but also have motivated new important research questions. For example, what is the general relationship between unemployment and mental health during the economic crisis in East Asian countries such as China? What is the specific relationship between unemployment and mental health during the economic crisis among migrant workers as the typical urban workforce in China, especially those who are unemployed and without unemployment insurance?

The present study seeks to go beyond existing studies to further examine mental health among unemployed migrant workers during the economic crisis by making the following four specific efforts.

First, we explore mental health in the Chinese context. Either economic boom [15] or crisis [16-19] can generate mental problems. Many Chinese people have suffered double distress from both rapid economic growth and an unprecedented economic crisis in the recent years. Lee's research group, for instance, found that economic contraction triggered by a global economic crisis of 2008 was associated with a higher risk of depression [20].

Second, we have chosen unemployed migrant workers as our subjects. In China, there are around 120 million rural-urban migrants, accounting for about $25 \%$ of the working population of the entire country [21]. The economic crisis of 2008 has forced thousands of labour-intensive enterprises to go bankrupt in China and hundreds of thousands of migrant workers to lose their jobs. According to China's National Statistics Bureau, by the end of 2008, the registered unemployed population in urban areas was 8.86 million, and about 20 million of 120 million peasants who went to cities for work in China have lost their jobs [22]. In recent years, the mental health of migrant workers in China has received close attention by researchers [21,23-25]. For example, in an important study, Wong and his collaborators evaluated the mental health status of 475 migrant workers in Shanghai by using the Brief Symptoms Inventory (BSI). They found that migrant workers experienced more stress in "interpersonal tensions and conflicts" and were more likely to be mentally unhealthy [23].

Third, we focus on two aspects of unemployed workers, their duration of unemployment and coping strategies used. First, duration of unemployment refers to the time period during which the person recorded as unemployed was seeking or available for work. The positive linear relationship between duration of unemployment and mental health has been well studied in a number of populations [26-29]. Stankunas' group, for instance, surveyed 429 unemployed persons in Lithuania and found that long-term unemployed persons had more episodes of depression in the past 12 months in comparison with short-term unemployed ones [26]. Second, coping strategies, according to the vulnerability-stress model proposed by Zubin and Spring [30], mediate the potentially negative effects of daily stressors and thus influence mental health $[31,32]$. The development of a successful coping behavior is likely to reduce stress and help a person to solve personal problems and maintain psychological balance and health [33]. People with a lower level of mental health have been shown to use more avoidance or other negative coping strategies, whereas people with a higher level of mental health use more problemfocused strategies aimed at dealing with the stressors themselves [32]. As one of the earliest empirical efforts, $\mathrm{Li}$ and his collaborators found that migrant workers were more inclined to turn to friends than family members and only in $1 \%$ of the cases sought professional help [21]. Thus, it is theoretically and practically important to examine duration of unemployment as a stressor and coping strategies as stress management skills in order to understand how unemployed migrant worker in China develop and deal with their mental problems.

The aims of the present paper were to (1) examine the frequency and severity of mental health problems among the unemployed migrant workers in Eastern China during the economic crisis and (2) evaluate the association of their mental health with unemployment duration and coping strategies. 


\section{Methods}

\section{Research design}

The cross-sectional design was used in the study. The longitudinal design has widely been used to observe the changes of mental health over long periods of time $[20,34]$. However, it is a unique challenge to use the longitudinal design to study unemployed migrant workers in China. It is simply infeasible in China to track unemployed migrant workers because they change their jobs frequently and no formal mechanisms such as social welfare registrars in China exist to find them, except for identifying them individually in the non-organized job seeking market. On the other hand, it is important to study mental health of unemployed migrant workers during, rather than after, an economic crisis. Moreover, cross-sectional studies allow one to compare the mental health of different types of unemployed groups at a single time point (e.g., the beginning of economic crisis).

Interview-based survey has frequently been used to study mental health issues [35-37] and was chosen in the study for two specific reasons. First, unemployed migrant workers in China do not need to have labor insurance in order to register in the local labor market. Unlike in many other countries where the majority of unemployed individuals register at governmental or municipally-run agencies for receiving unemployment compensation, unemployment insurance is usually provided for the urban dwellers in China. It is impossible to use the telephone-based interview because of the lack of any information on individual unemployed migrant workers (such as telephone numbers). Thus, the best way for us to find interviewees is to concentrate on the labour markets and wait for these migrant job hunters. Second, many of unemployed migrant workers in China do not understand the meaning of psychological questionnaires due to their semi literacy or illiteracy.

\section{Participants}

Migrant workers were defined in the study as those who were 18 years of age or older, possess a legal rural hukou (“户口”, formally registered permanent residents in a rural area in China), and have been granted the legal right to work temporarily in urban and prosperous coastal regions for at least six months. Unemployed workers, as defined by the International Labour Organization, refers to people who are without jobs and have been actively looking for work within the past four weeks [38]. These criteria were used in the study to identify participants.

We use the following method [39] to determine the sample size: Sample Size $=n /[1+(\mathrm{n} /$ population $)]$ while $\mathrm{n}=\mathrm{Z} * \mathrm{Z}[\mathrm{P}(1-\mathrm{P}) /(\mathrm{D} * \mathrm{D})]$. Here, $\mathrm{Z}=1.960$ with Confidence Level of 95\%; P (Expected Frequency Value) = $43.6 \%$, based on our pilot study that the positive symptom detection rate of SCL-90 in the unemployed migrant workers is $43.6 \%$ ); $\mathrm{D}$ (Maximum difference between the sample mean and the population mean) $=0.15 \mathrm{P}=0.0654$. Thus, the estimated sample size $=220$. A total of 232 unemployed migrant workers were identified by convenience sampling for the interview-based survey. Among them, 22 individuals (9\%) declined to participate and 210 individuals (91\%) filled out all the questionnaires, which was the final sample size of the study.

\section{Measurement \\ Socio-demographics}

A demographic questionnaire elicited basic background information, including age, gender, marital status, education, region of origin, household register, type of last job and other basic demographic information.

\section{Duration of unemployment}

The duration of unemployment was assessed by asking for the number of months unemployed altogether. Short-term unemployment is defined in this study as less than three months; long-term is greater than three months [38].

\section{Mental health}

Mental health status was measured by the Chinese version [40] of the Symptom Checklist-90-Revised (SCL-90-R) [41]. It is the most widely used instrument in China to examine mental disorders. From 1986 to 2007, there were over 500 independent studies used by SCL-90-R in China [42]. The SCL-90-R is a 90-item self-report symptom inventory designed to screen for a broad range of psychological problems. Each of the 90 items is rated on a five-point scale of distress, ranging from "not at all" (1) to "extremely" (5). The answers are combined in nine primary symptom dimensions: Somatization(SOM), Obsessive-Compulsive(O-C), Interpersonal Sensitivity(I-S), Hostility(HOS), Depression(DEP), Anxiety(ANX), Paranoid Ideation(PAR), Phobic Anxiety (PHOB) and Psychoticism(PSY). The internal consistency coefficient alphas for the nine symptom dimensions in the study ranged from $0.75-0.88$. In addition, the severity of psychiatric and psychosomatic symptoms was defined by the score of the global severity index (GSI) [40]. Individual respondents who had GSI total scores greater than 70 points were considered to have poor mental health.

\section{Coping strategy}

Coping strategies were measured using an adapted Coping Strategies Questionnaire (CSQ) by Xiao and Xu [43], which was a revised version of a questionnaire developed by Folkman and Lazarus [44]. It contains 62 items to assess six factors, problem-solving, self-blaming, help-seeking, fantasizing, avoidance, and rationalization. These six factors comprise three types of coping strategies, immature 
type (self-blaming, fantasizing, and avoidance), mixed type (rationalization), and mature type (problem-solving, help-seeking). Internal consistency coefficients alphas obtained in the study were 0.80 for problem-solving, 0.82 for self-blaming, 0.85 for help-seeking, 0.81 for fantasizing, 0.80 for avoidance, and 0.90 for rationalization.

\section{Procedure}

During the period from December 2008 to April 2009, unemployed migrant workers were identified and recruited in the recruitment hall of the buildings of two largest labor markets in two cities, Wenzhou and Ningbo, Zhejiang Provience, China. These two cities in Zhejiang Province were chosen as the study site because Zhejiang was the one of most seriously hit areas in China during the economic crisis of 2008; $20 \%$ of small and medium enterprises of Zhejiang was closed down, especially in Wenzhou and Ningbo.

The present study consisted of the following steps. First, in the pilot study, the questionnaire was pre-tested with 30 unemployed migrant workers from the labor market in the city of Wenzhou. Eight participants were unable to finish the questionnaire independently and found that many of them simply did not understand the meaning of psychological questionnaires due to their semi literacy or illiteracy. As a result, we decided to study the subjects by a face-to-face structured interview rather than a paper-pencil survey. Second, in the formal study, four questions were asked as the inclusion criteria: Where are you from? Do you possess the rural hukou or urban hukou? Are you unemployed? Do you lost your job at least one month? Only subjects who met these criteria were asked to complete the study. Third, the interview was conducted in the quiet and comfortable office rooms in the labour markets because it provided adequate privacy and was convenient to the participants. Before each interview, the eligible participant was explained about the purpose and the procedure of the study and asked for their consent. The individual-based face-to-face interview took approximately 30 minutes and was conducted by trained researchers, including faculty members and postgraduate students from Wenzhou Medical College. Systematic training was provided before these researchers were dispatched to the field to conduct the interviews. Fourth, upon completion, each of participants was given a tooth brush and a tooth paste as a token of appreciation.

This study was done in compliance with the Helsinki Declaration, and was reviewed and approved by the Ethics Committee of Wenzhou Medical College.

\section{Data analysis}

First, we created dichotomous variables (unhealthy vs. healthy) for each subscale of SCL-90-R, considering subscale scores $>2$ or total scores of global severity index (GSI) $>70$ as suggestive of possible psychopathology. Second, independent sample t tests were conducted with each SCL-90-R subscale between the unemployed migrant worker samples and the Chinese adult norm of 1986 [42], 2003 [45] and 2006 [42]. Third, we compared scores of SCL-90-R sub-scales among long-term, shortterm unemployed migrant workers and employed migrant workers by two One-Way Analysis of Variance (ANOVA). The data source of employed migrant workers came from the research of Liao's group, in which 345 employed migrant workers in Wenzhou were measured by SCL-90-R during the economic crisis of 2008 [46]. Fourth, two ANOVA also were carried out on each SCL90-R subscale among three groups by types of coping strategy. Finally, hierarchical regression analysis was used to measure the effects of the related factors on mental health.

\section{Results}

Socio-demographics of the unemployed migrant workers Of the 210 respondents, 135 (64.3\%) were males and 75 (35.7\%) females, 116(55\%) of unemployed migrant workers were younger than 30 , and over one-third of them were single. Most of the unemployed migrants only had a junior secondary school education (5-8 years of schooling) or below, and 138 (65.7\%) of them were short-term unemployed migrant workers. About $86.7 \%$ of these migrant workers worked as manufacturing industry workers and $7.6 \%$ as service industry workers. The prevalence of main social and demographic characteristics by type of unemployment is presented in Table 1. It demonstrates that the majority of the unemployed migrant workers were young male manufacturing industry workers with short-term unemployment and a relatively low education level.

\section{Mental health of the unemployed migrant workers}

In general, as shown in Figure 1, the mean SCL-90-R GSI scores for all 210 unemployed migrant workers was above the cut-off point (GSI $>70)$, with a positive skewed distribution, 94 (45\%) had a GSI > 70, indicating marked psychological distress and probable psychological/psychiatric illness.

Specifically, according to the criteria (subscale scores > 2 as suggestive of possible psychopathology), 107(51\%) had a DEP $>2,102(49 \%)$ had a PAR $>2,101(48 \%)$ had a HOS $>2$, $91(43 \%)$ had a INS $>2,84(40 \%)$ had a O-C $>2$, $77(37 \%)$ had a ANX $>2,70(33 \%)$ had a $\mathrm{SOM}>2,53$ (25\%) had a PSY $>2$, and $42(20 \%)$ had a PHOB $>2$.

To determine whether the unemployed migrant workers would report elevated levels of distress compared with the adult norm in China, independent t-tests were conducted with each SCL-90-R subscale. As shown in 
Table 1 Socio-demographics of the unemployed migrant workers $(N=210)$

\begin{tabular}{|c|c|c|c|}
\hline Variables & & $n$ & $\%$ \\
\hline \multirow[t]{2}{*}{ Gender } & Men & 135 & 64.3 \\
\hline & Women & 75 & 35.7 \\
\hline \multirow[t]{4}{*}{ Age groups } & $<20$ & 25 & 11.9 \\
\hline & $21-30$ & 91 & 43.3 \\
\hline & $31-40$ & 60 & 28.6 \\
\hline & $>41$ & 34 & 16.2 \\
\hline \multirow[t]{3}{*}{ Marital status } & Single & 72 & 34.3 \\
\hline & Married/Cohabiting & 122 & 58.1 \\
\hline & Divorced/Widowed & 16 & 7.6 \\
\hline \multirow[t]{4}{*}{ Education } & $<5$ years or illiteracy & 24 & 11.4 \\
\hline & $5-8$ years & 98 & 46.7 \\
\hline & 9-11 years & 62 & 29.5 \\
\hline & $>11$ years & 26 & 12.4 \\
\hline \multirow[t]{6}{*}{ Type of last job } & Shoe industry & 91 & 43.3 \\
\hline & Grasses industry & 48 & 22.9 \\
\hline & Closing industry & 41 & 19.5 \\
\hline & Mechanical industry & 2 & 1.0 \\
\hline & Catering & 16 & 7.6 \\
\hline & Others & 12 & 5.7 \\
\hline \multirow[t]{6}{*}{ region of origin } & Jiangxi province & 48 & 22.8 \\
\hline & Anhui province & 36 & 17.1 \\
\hline & Hunan province & 39 & 18.6 \\
\hline & Henan province & 24 & 11.4 \\
\hline & Sichuan province & 25 & 11.9 \\
\hline & Other provinces & 38 & 18.1 \\
\hline \multirow[t]{2}{*}{ Duration of unemployment } & $\leq 3$ months & 138 & 65.7 \\
\hline & $>3$ months & 72 & 34.3 \\
\hline
\end{tabular}

Table 2, on all nine clinical subscales of SCL-90-R, unemployed migrant workers scored significantly higher than the adult norms of 1986 [42], 2003 [45] and 2006 [42].

\section{Mental health and duration of unemployment}

The correlation matrix presented in Table 3 revealed that duration of unemployment has significant positive correlations with anxiety $(\mathrm{r}=0.22, \quad p<0.01)$, paranoid ideation $(\mathrm{r}=0.19, p<0.01)$, psychoticism $(\mathrm{r}=0.20, p<0.01)$. As shown in Table 4, unemployed migrant workers expressed significantly more symptoms of psychological distress in nine SCL-90-R subscales, whether it is shortterm or long-term unemployment. Long-term unemployed migrant workers expressed significantly more symptoms of psychological distress than short-term unemployed (somatization, anxiety, phobic anxiety, paranoid ideation, psychoticism). To further illustrate Table 4, Figure 2 depicts the SCL-90-R profile for long-term unemployed, short-term unemployed and employed migrant workers.

\section{Mental health and coping strategy of unemployed migrant workers}

The most frequently used coping strategies by the unemployed migrant workers were problem-solving $(0.73 \pm$ $0.20)$, followed by avoidance ( $0.62 \pm 0.16)$, rationalization $(0.61 \pm 0.17)$, fantasizing $(0.56 \pm 0.21)$, help-seeking $(0.55 \pm$ $0.19)$ and self-blaming $(0.48 \pm 0.28)$.

The correlation matrix presented in Table 3 revealed that there are significant associations between the coping strategies and mental health symptoms of unemployed migrant workers. As shown in Table 5, unemployed migrant workers with immature type of coping strategy expressed significantly more symptoms of psychological distress compared to unemployed migrant workers with mixed or mature type of coping strategy in nine SCL-90-R subscales. Unemployed migrant workers with mixed type of coping strategy also expressed a more pronounced symptom load when compared to mature type group in interpersonal sensitivity, depression, hostility, paranoid ideation, and psychoticism. To further illustrate Table 5, Figure 3 depicts the profile of SCL-90-R scores for different types of coping strategy.

\section{Hierarchical regression analysis for predicting GSI}

As shown in Table 6, duration of unemployment and two coping strategies, problem-solving and self-blaming, significantly predicted the mental health of the unemployed migrant workers. Duration of unemployment contributed to about $5 \%$ of the variance in total scores of GSI and problem-solving and self-blaming explained over $33 \%$ of the variance in total scores of GSI.

\section{Discussion}

\section{Limitations of the study}

Four limitations are present prior to proceeding with the discussion on the results of this study. First, we used a convenience sampling method, which may limit the generalizablity of the findings to the target population. Second, data were self-reported in nature and may be subject to reporting bias, although most mental health studies are in fact self-reported. Third, this study did not collect the job characteristics (i.e., duration of last job) that may have an association with mental health status during unemployment, an important topic for future studies. Fourth, this study is not longitudinal. The characteristic of migrant workers did not permit follow-ups of the participants during their full unemployment period for an evaluation of their mental health. 


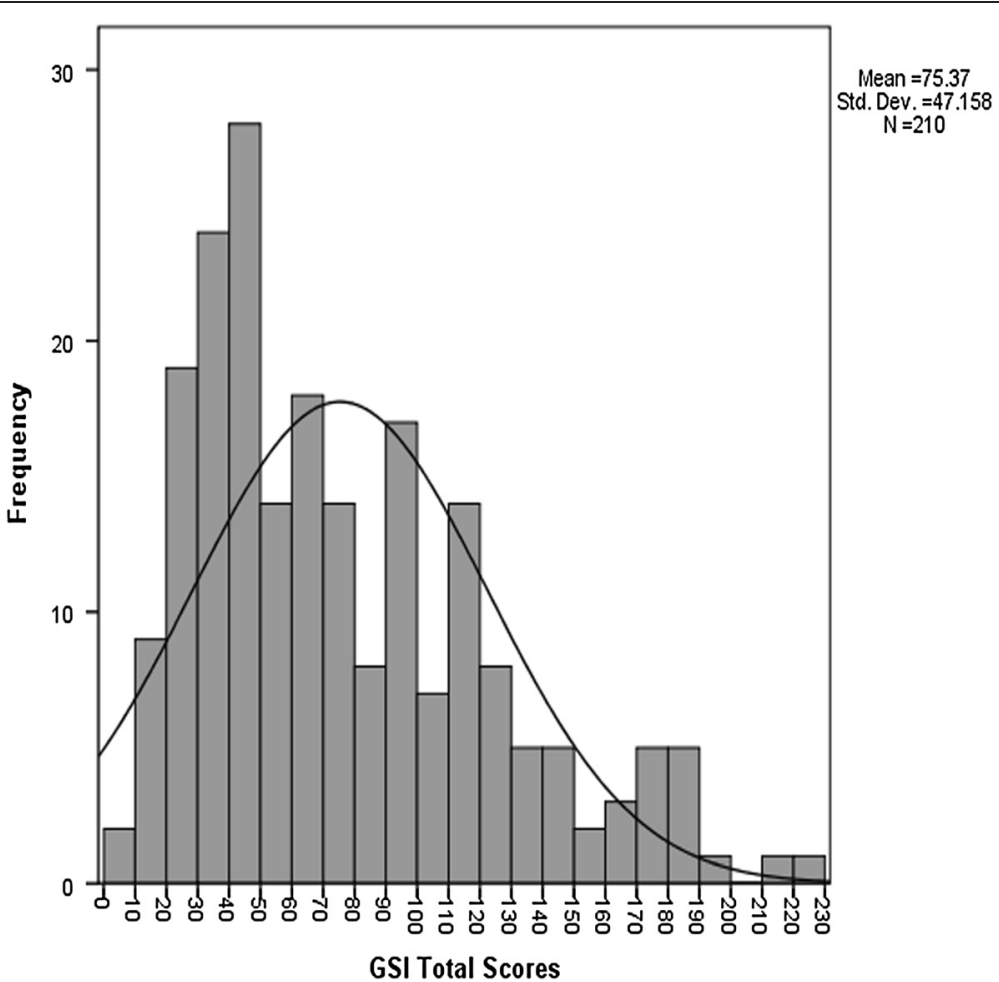

Figure 1 Distribution of GSI total scores. Histogram showing the distribution of the Symptom Checklist-90-Revised (SCL-90-R) global severity index (GSI) total scores in the unemployed migrant workers. GSI total scores $>70$ identify cases with possible mental disorder (SCL cases: $n=94$ out of 210 subjects).The $y$-axis shows the number of individuals with a GSI score in the ranges of the GSI indicated in the x-axis (note that ten GSI points are condensed into one category on the x-axis).For example, 26 subjects had a GSI score in the range of 60-70.The range of the observed scores was 0-230, Mean $=75.37, \mathrm{SD}=47.16$.

Table 2 Comparison of scores of SCL-90-R sub-scales between the unemployed migrant workers and the adult norm

\begin{tabular}{|c|c|c|c|c|c|c|c|c|c|c|}
\hline & & \multicolumn{9}{|c|}{ Scores of SCL-90-R sub-scales $(M \pm S D)$} \\
\hline & & SOM & O-C & INS & DEP & ANX & HOS & PHOB & PAR & PSY \\
\hline $\begin{array}{l}\text { Samples of } \\
\text { unemployed } \\
\text { migrant } \\
\text { workers }\end{array}$ & $(N=210)$ & $1.73 \pm 0.59$ & $1.95 \pm 0.64$ & $1.92 \pm 0.55$ & $2.02 \pm 0.04$ & $1.81 \pm 0.58$ & $1.97 \pm 0.74$ & $1.56 \pm 0.59$ & $1.98 \pm 0.58$ & $1.64 \pm 0.55$ \\
\hline $\begin{array}{l}\text { The adult norm } \\
\text { of } 1986^{\circ}\end{array}$ & $(N=1388)$ & $1.37 \pm 0.48$ & $1.62 \pm 0.58$ & $1.65 \pm 0.61$ & $1.50 \pm 0.59$ & $1.39 \pm 0.43$ & $1.46 \pm 0.55$ & $1.23 \pm 0.41$ & $1.43 \pm 0.57$ & $1.29 \pm 0.42$ \\
\hline$t^{l}$ & & $1.88^{* * *}$ & $7.44^{* * *}$ & $7.28^{* * *}$ & $12.35^{* * *}$ & $10.61^{* * *}$ & $9.97^{* * *}$ & $8.15^{* * *}$ & $13.91^{* * *}$ & $9.16^{* * *}$ \\
\hline $\begin{array}{l}\text { The adult norm } \\
\text { of } 2003^{b}\end{array}$ & $(N=2808)$ & $1.36 \pm 0.39$ & $1.47 \pm 0.45$ & $1.44 \pm 0.45$ & $1.33 \pm 0.39$ & $1.30 \pm 0.37$ & $1.36 \pm 0.41$ & $1.17 \pm 0.30$ & $1.32 \pm 0.42$ & $1.25 \pm 0.34$ \\
\hline$t^{2}$ & & $8.99^{* * *}$ & $10.84^{* * *}$ & $12.86^{* * *}$ & $16.37^{* * *}$ & $12.88^{* * *}$ & $11.94^{* * *}$ & $9.61^{* * *}$ & $16.67^{* * *}$ & $10.22^{* * *}$ \\
\hline $\begin{array}{l}\text { The adult norm } \\
\text { of } 2006^{c}\end{array}$ & $(N=1890)$ & $1.42 \pm 0.44$ & $1.66 \pm 0.52$ & $1.51 \pm 0.49$ & $1.49 \pm 0.47$ & $1.34 \pm 0.39$ & $1.49 \pm 0.51$ & $1.27 \pm 0.39$ & $1.44 \pm 0.47$ & $1.33 \pm 0.39$ \\
\hline$t^{3}$ & & $7.54^{* * *}$ & $6.53^{* * *}$ & $10.99^{* * *}$ & $12.59^{* * *}$ & $11.87^{* * *}$ & $9.38^{* * *}$ & $7.16^{* * *}$ & $13.66^{* * *}$ & $8.112^{* * *}$ \\
\hline
\end{tabular}

Note: ${ }^{*} p<0.05{ }^{* *} p<0.01{ }^{* * *} p<0.001$.

${ }^{1}$ Comparison of Scores of SCL-90-R Sub-scales between the unemployed migrant workers and the adult norm of 1986.

${ }^{2}$ Comparison of Scores of SCL-90-R Sub-scales between the unemployed migrant workers and the adult norm of 2003.

${ }^{3}$ Comparison of Scores of SCL-90-R Sub-scales between the unemployed migrant workers and the adult norm of 2006.

a, c For the data source, see reference No.42.

${ }^{\mathrm{b}}$ For the data source, see reference No.45.

SOM Somatization, INS Interpersonal Sensitivity, ANX AnxietyPHOB: Phobic Anxiety, PSY Psychoticism.

O-C Obsessive-Compulsive, DEP Depression, HOS Hostility, PAR Paranoid Ideation, SCL-90-R Symptom Checklist-90-Revised. 
Table 3 Intercorrelations among variables used in this study $(N=210)$

\begin{tabular}{|c|c|c|c|c|c|c|c|c|c|c|c|c|c|c|c|c|c|c|c|}
\hline & 1 & 2 & 3 & 4 & 5 & 6 & 7 & 8 & 9 & 10 & 11 & 12 & 13 & 14 & 15 & 16 & 17 & 18 & 19 \\
\hline 1.Gender & - & & & & & & & & & & & & & & & & & & \\
\hline 2.Age & -.09 & - & & & & & & & & & & & & & & & & & \\
\hline 3.Marital status & $-.20^{* *}$ & $.67^{* *}$ & - & & & & & & & & & & & & & & & & \\
\hline 4.Education & .06 & .00 & .02 & - & & & & & & & & & & & & & & & \\
\hline 5.Problem-solving & $-.19^{* *}$ & $.22^{* *}$ & .10 & .12 & - & & & & & & & & & & & & & & \\
\hline 6.Self-blame & -.05 & $-.21^{* *}$ & -.06 & -.05 & $-.33^{* *}$ & - & & & & & & & & & & & & & \\
\hline 7.Help-seeking & $-.14^{*}$ & -.01 & .04 & -.03 & $.23 * *$ & -.02 & - & & & & & & & & & & & & \\
\hline 8.Fantasizing & -.06 & -.12 & .06 & .02 & $-.25^{* *}$ & $.62^{* *}$ & -.03 & - & & & & & & & & & & & \\
\hline 9.Avoidance & -.02 & .11 & .12 & .03 & $.19^{* *}$ & $.30^{* *}$ & .07 & $.31^{* *}$ & - & & & & & & & & & & \\
\hline 10.Rationalization & -.12 & -.12 & .06 & .08 & -.11 & $.66^{* *}$ & .10 & $.66^{* *}$ & $.40^{* *}$ & - & & & & & & & & & \\
\hline 11.Duration unemployment & -.06 & .06 & .06 & .11 & $-.29^{* *}$ & .03 & -.12 & .10 & -.11 & .01 & - & & & & & & & & \\
\hline $12.5 O M$ & .06 & -.07 & -.01 & -.13 & $-.49^{* *}$ & $.35^{* *}$ & .04 & $.31^{* *}$ & -.12 & $.19^{* *}$ & $.34 * *$ & - & & & & & & & \\
\hline 13.O-C & .11 & $-.21^{* *}$ & $-.25^{* *}$ & $-01^{*}$ & $-.45^{* *}$ & $.44^{* *}$ & -.01 & $.29 * *$ & .04 & $.17^{*}$ & .13 & $.66^{* *}$ & - & & & & & & \\
\hline 14.INS & .06 & $-.19^{* *}$ & $-.16^{*}$ & -.13 & $-32^{* *}$ & $.55^{* *}$ & -.03 & $.38^{* *}$ & $.16^{*}$ & $.29^{* *}$ & .09 & $.59^{* *}$ & $.77^{* *}$ & - & & & & & \\
\hline 15.DEP & .02 & -.07 & -.07 & -.09 & $-.31^{* *}$ & $.57^{* *}$ & -.09 & $.32^{* *}$ & $.19^{* *}$ & $.29^{* *}$ & .09 & $.65^{* *}$ & $.78^{* *}$ & $.80^{* *}$ & - & & & & \\
\hline 16.ANX & .13 & -.11 & -.07 & -.07 & $-.47^{* *}$ & $.42^{* *}$ & -.03 & $.35^{* *}$ & -.02 & $.22^{* *}$ & $.22^{* *}$ & $.82^{* *}$ & $.79 * *$ & $.75^{* *}$ & $.79 * *$ & - & & & \\
\hline $17 . \mathrm{HOS}$ & $.23^{* *}$ & $-.25^{* *}$ & $-.15^{*}$ & -.02 & $-.39^{* *}$ & $.46^{* *}$ & .12 & $.36^{* *}$ & $20 * *$ & $.40^{* *}$ & .12 & $.62^{* *}$ & $.65^{* *}$ & $.67^{* *}$ & $.70^{* *}$ & $.72^{* *}$ & - & & \\
\hline 18.PHOB & .11 & -.05 & -.06 & -.10 & $-.53^{* *}$ & $.46^{* *}$ & -.06 & $.36^{* *}$ & -.09 & $.21^{* *}$ & $.23^{* *}$ & $.78^{* *}$ & $.71^{* *}$ & $.75^{* *}$ & $.69^{* *}$ & $.78^{* *}$ & $.58^{* *}$ & - & \\
\hline 19.PAR & $.19^{* *}$ & $-.14^{*}$ & -.11 & -.02 & $-.39 * *$ & $.53^{* *}$ & -.04 & $.41^{* *}$ & $.16^{*}$ & $.34^{* *}$ & $.19 * *$ & $.67^{* *}$ & $.74^{* *}$ & $.79^{* *}$ & $.82^{* *}$ & $.77^{* *}$ & $.76^{* *}$ & $.74^{* *}$ & - \\
\hline 20.PSY & $.22^{* *}$ & $-.17^{*}$ & -.13 & -.12 & $-.49^{* *}$ & $.51^{* *}$ & .01 & $.34^{* *}$ & -.08 & $.24^{* *}$ & $20 * *$ & $.79^{* *}$ & $.77^{* *}$ & $.74^{* *}$ & $.68^{* *}$ & $.83^{* *}$ & $.65^{* *}$ & $.82^{* *}$ & $.78^{* *}$ \\
\hline
\end{tabular}

Mental health of the unemployed migrant workers

This study is the first estimation of prevalence of mental problems among unemployed migrant workers in Eastern China. It is found that as high as 50 percent of the unemployed migrant workers are classified as mentally unhealthy. Compared with the SCL-90-R adult norm of 1986, 2003, and 2006 in China, the unemployed migrant workers exhibited much poorer mental health and the

Table 4 Comparison of Scores of SCL-90-R sub-scales among long-term, short-term unemployed migrant workers and employed migrant workers

\begin{tabular}{|c|c|c|c|c|c|c|c|}
\hline \multirow{2}{*}{$\begin{array}{l}\text { SCL-90-R } \\
\text { sub-scales }\end{array}$} & \multicolumn{3}{|c|}{$M \pm S D$} & \multirow[t]{2}{*}{$F$} & \multirow[b]{2}{*}{$\begin{array}{c}\text { Mean } \\
\text { difference } \\
\text { between } \\
\text { long-term } \\
\text { unemployed } \\
\text { and short-term } \\
\text { unemployed }\end{array}$} & \multirow{2}{*}{$\begin{array}{c}\text { Mean } \\
\text { difference } \\
\text { between } \\
\text { long-term } \\
\text { unemployed } \\
\text { and employed }\end{array}$} & \multirow{2}{*}{$\begin{array}{c}\text { Mean } \\
\text { difference } \\
\text { between } \\
\text { short-term } \\
\text { unemployed } \\
\text { and employed }\end{array}$} \\
\hline & $\begin{array}{l}\text { Long-term } \\
\text { unemployed migrant } \\
\text { workers }(n=73)\end{array}$ & $\begin{array}{c}\text { Short-term } \\
\text { unemployed migrant } \\
\text { workers }(n=137)\end{array}$ & $\begin{array}{c}\text { Employed } \\
\text { migrant } \\
\text { workers }^{\mathrm{a}}(n=347)\end{array}$ & & & & \\
\hline SOM & $2.00 \pm 0.64$ & $1.58 \pm 0.51$ & $1.43 \pm 0.42$ & $43.68^{* * *}$ & $0.42^{* * *}$ & $0.57^{* * *}$ & $0.15^{* *}$ \\
\hline $\mathrm{O}-\mathrm{C}$ & $2.06 \pm 0.59$ & $1.89 \pm 0.66$ & $1.76 \pm 0.56$ & $8.97^{* * *}$ & $0.17^{*}$ & $0.31^{* * *}$ & $0.13^{*}$ \\
\hline INS & $1.99 \pm 0.56$ & $1.89 \pm 0.54$ & $1.49 \pm 0.49$ & $45.69^{* * *}$ & 0.10 & $0.49^{* * *}$ & $0.39^{* * *}$ \\
\hline$\overline{D E P}$ & $2.10 \pm 0.69$ & $1.98 \pm 0.56$ & $1.57 \pm 0.56$ & $40.10^{* * *}$ & 0.11 & $0.52^{* * *}$ & $0.41^{* * *}$ \\
\hline ANX & $1.98 \pm 0.59$ & $1.72 \pm 0.54$ & $1.49 \pm 0.47$ & $32.31^{* * *}$ & $0.26^{* * *}$ & $0.49^{* * *}$ & $0.23^{* * *}$ \\
\hline $\mathrm{HOS}$ & $2.08 \pm 0.81$ & $1.90 \pm 0.69$ & $1.57 \pm 0.57$ & $26.21^{* * *}$ & 0.18 & $0.50^{* * *}$ & $0.33^{* * *}$ \\
\hline $\mathrm{PHOB}$ & $1.75 \pm 0.67$ & $1.46 \pm 0.52$ & $1.40 \pm 0.46$ & $14.00^{* *}$ & $0.28^{* * *}$ & $0.37^{* * *}$ & 0.06 \\
\hline PAR & $2.13 \pm 0.58$ & $1.90 \pm 0.56$ & $1.52 \pm 0.49$ & $56.67^{* * *}$ & $0.23^{* *}$ & $0.61^{* * *}$ & $0.38^{* * *}$ \\
\hline PSY & $1.79 \pm 0.53$ & $1.56 \pm 0.55$ & $1.47 \pm 0.48$ & $12.55^{* * *}$ & $0.24^{* *}$ & $0.32^{* * *}$ & 0.09 \\
\hline
\end{tabular}

Note: ${ }^{*} p<0.05^{* *} p<0.01{ }^{* * *} p<0.001$.

${ }^{a}$ For the data source, see reference No.46.

SOM Somatization, INS Interpersonal Sensitivity, ANX Anxiety, PHOB Phobic Anxiety, PSY Psychoticism.

O-C Obsessive-Compulsive, DEP Depression, HOS Hostility, PAR Paranoid Ideation, SCL-90-R Symptom Checklist-90-Revised. 


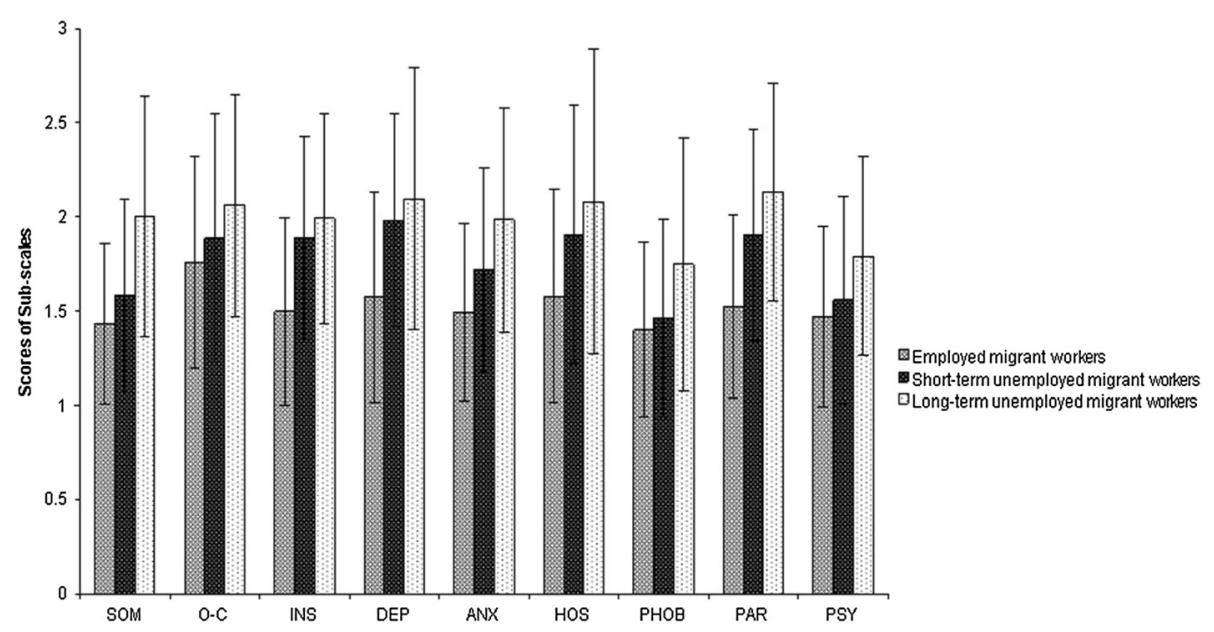

Figure 2 Symptom profile (SCL-90-R sub-scales) for employed, short-term unemployed and long-term unemployed migrant workers. SCL-90-R: Symptom Checklist-90-Revised; SOM: Somatization; O-C: Obsessive-Compulsive; I-S: Interpersonal Sensitivity; DEP: Depression; ANX: Anxiety; HOS: Hostility; PHOB: Phobic Anxiety; PAR: Paranoid Ideation; PSY: Psychoticism.

most frequently reported item was depression. The prevalence rate found in the study is much higher than that reported in previous studies [23,24]. For instance, in the study conducted by Wong et al, $31 \%$ migrant workers in China were classified as mentally unhealthy [23].

Both unemployment status and migration status might explain the high prevalence rate of mental problems among unemployed migrant workers in Eastern China. First, during the economic crisis, as the existing literature has indicated $[6,8]$, unemployed individuals have witnessed the loss of property and jobs as well as social disruption and increasing deterioration of quality of life and well-being. These adverse changes were significantly associated with mental health problems, particularly with depression. Second, migration stress entails tremendous social and economic cost but with uncertain benefit. It has often been seen as a potential risk factor that can increase the likelihood of poor mental health outcomes [47]. In China, because of the hukou system, migrant workers cannot register as formal residents in cities and therefore are not entitled to subsidized housing, education, social security, or medical benefits. Studies also suggest that they tend to live in poorly sanitized and usually overcrowded dormitories $[23,24]$. Thus, unemployed migrant workers in China have to face double pressures due to their unemployment

Table 5 Comparison of Scores of SCL-90-R sub-scales among unemployed migrant workers with three types of coping strategy

\begin{tabular}{|c|c|c|c|c|c|c|c|}
\hline \multirow{2}{*}{$\begin{array}{l}\text { SCL-90-R } \\
\text { sub-scales }\end{array}$} & \multicolumn{3}{|c|}{ Type of coping strategy $(M \pm S D)$} & \multirow[t]{2}{*}{$F$} & \multirow{2}{*}{$\begin{array}{c}\text { Mean } \\
\text { difference } \\
\text { between } \\
\text { mature type } \\
\text { and mixed } \\
\text { type }\end{array}$} & \multirow{2}{*}{$\begin{array}{c}\text { Mean } \\
\text { difference } \\
\text { between } \\
\text { mature } \\
\text { type and } \\
\text { immature type }\end{array}$} & \multirow{2}{*}{$\begin{array}{c}\text { Mean } \\
\text { difference } \\
\text { between } \\
\text { mixed type } \\
\text { and immature } \\
\text { type }\end{array}$} \\
\hline & $\begin{array}{c}\text { Mature } \\
\text { type }(n=63)\end{array}$ & $\begin{array}{c}\text { Mixed } \\
\text { type }(n=103)\end{array}$ & $\begin{array}{l}\text { Immature } \\
\text { type }(n=42)\end{array}$ & & & & \\
\hline SOM & $1.57 \pm 0.43$ & $1.72 \pm 0.58$ & $2.01 \pm 0.73$ & $7.30^{* *}$ & -0.15 & $-0.44^{* * *}$ & $-0.28 * *$ \\
\hline $\mathrm{O}-\mathrm{C}$ & $1.76 \pm 0.52$ & $1.89 \pm 0.63$ & $2.36 \pm 0.65$ & $13.16^{* * *}$ & -0.13 & $-0.59 * * *$ & $-0.05^{* * *}$ \\
\hline INS & $1.64 \pm 0.47$ & $1.92 \pm 0.49$ & $2.35 \pm 0.51$ & $26.38^{* * *}$ & $-0.28^{* * *}$ & $-0.71^{* * *}$ & $0.43^{* * *}$ \\
\hline DEP & $1.72 \pm 0.58$ & $2.03 \pm 0.52$ & $2.46 \pm 0.62$ & $21.94^{* * *}$ & $-0.37^{* *}$ & $-0.74^{* *}$ & $-0.43^{* * *}$ \\
\hline ANX & $1.66 \pm 0.48$ & $1.76 \pm 0.55$ & $2.18 \pm 0.63$ & $12.37^{* * *}$ & -0.10 & $-0.52^{* * *}$ & $-0.42^{* * *}$ \\
\hline $\mathrm{HOS}$ & $1.55 \pm 0.55$ & $1.99 \pm 0.71$ & $2.51 \pm 0.69$ & $26.85^{* * *}$ & $-0.44^{* * *}$ & $-0.96^{* * *}$ & $-0.52^{* *}$ \\
\hline $\mathrm{PHOB}$ & $1.35 \pm 0.28$ & $1.54 \pm 0.62$ & $1.92 \pm 0.72$ & $12.76^{* * *}$ & $-0.19^{*}$ & $-0.56^{* * *}$ & $-0.37^{* * *}$ \\
\hline PAR & $1.69 \pm 0.49$ & $1.97 \pm 0.52$ & $2.48 \pm 0.51$ & $30.83^{* * *}$ & $-0.27^{* * *}$ & $-0.79 * *$ & $-0.53^{* * *}$ \\
\hline PSY & $1.42 \pm 0.35$ & $1.59 \pm 0.56$ & $2.07 \pm 0.56$ & $21.58^{* * *}$ & $-0.17^{* * *}$ & $-0.65^{* * *}$ & $-0.48^{* * *}$ \\
\hline
\end{tabular}

Note: ${ }^{*} p<0.05^{* *} p<0.01{ }^{* * *} p<0.001$.

SOM Somatization, INS Interpersonal Sensitivity, ANX Anxiety, PHOB Phobic Anxiety, PSY Psychoticism.

O-C Obsessive-Compulsive, DEP Depression, HOS Hostility, PAR Paranoid Ideation, SCL-90-R Symptom Checklist-90-Revised. 


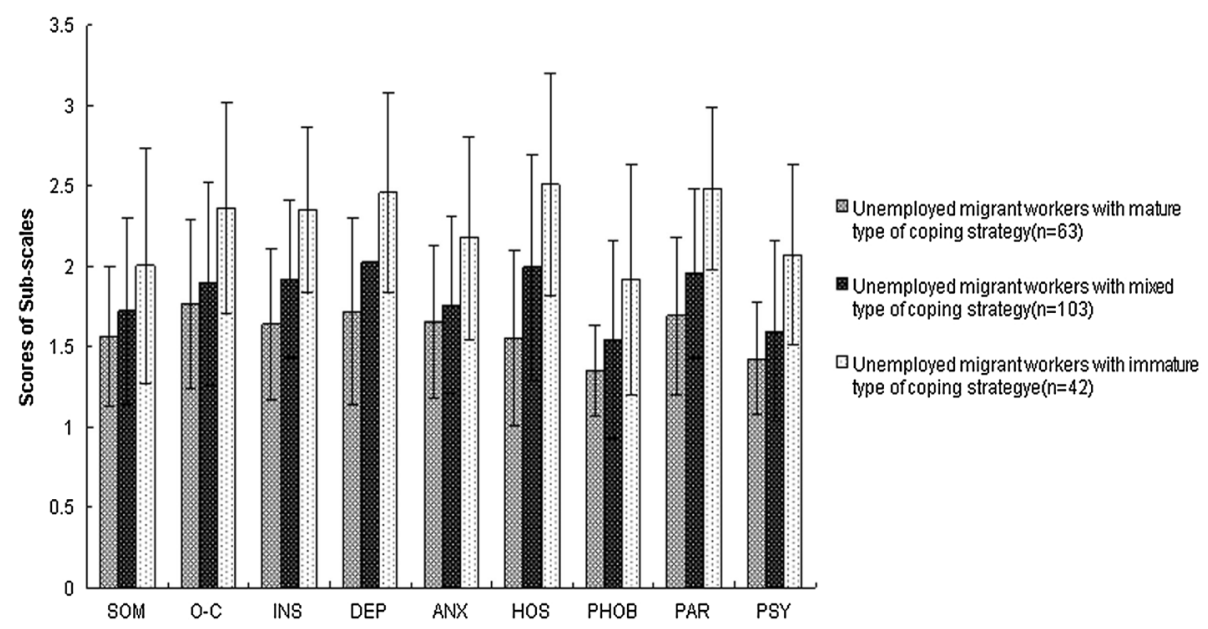

Figure 3 Symptom profile (SCL-90-R sub-scales) for unemployed migrant workers with three types of coping strategy. Figure 3 presented the three groups of unemployed migrant workers (shaded bars): unemployed migrant workers with mature type of coping strategy, unemployed migrant workers with mixed type of coping strategy, and unemployed migrant workers with immature type of coping strategy. SCL-90-R: Symptom Checklist-90-Revised; SOM: Somatization; O-C: Obsessive-Compulsive; I-S: Interpersonal Sensitivity; DEP: Depression; ANX: Anxiety; HOS: Hostility; PHOB: Phobic Anxiety; PAR: Paranoid Ideation; PSY: Psychoticism.

and migration status, leading to a high rate of mental problems.

\section{Mental health and duration of unemployment}

There are two major findings in the study relevant to mental health and duration of unemployment in this study. First, in line with the earlier findings in Western countries $[4,10,27]$, our study found that unemployed migrant workers expressed significantly more symptoms of psychological distress, compared with the employed migrant workers in China. Second, the mental problems of long-term unemployed migrant workers were more serious than that of short-term ones. These results are consistent with some of the previous research into long-term

Table 6 Results of hierarchical regression analysis $(N=210)$

\begin{tabular}{|c|c|c|c|c|c|}
\hline \multicolumn{2}{|c|}{ Independent variables } & \multicolumn{4}{|c|}{ GSI total score } \\
\hline & & \multirow[t]{2}{*}{ Step1 } & \multirow[t]{2}{*}{ Step2 } & \multicolumn{2}{|c|}{ Step3 } \\
\hline & & & & B (SE) & $\beta^{a}$ \\
\hline \multirow[t]{4}{*}{ 1. Control variables } & Gender & & & $11.57^{*}(5.64)$ & 0.12 \\
\hline & Age & & & $4.30(3.98)$ & 0.08 \\
\hline & Marital status & & & $-11.17(7.41)$ & -0.11 \\
\hline & Education(years) & & & $-3.72(3.07)$ & -0.07 \\
\hline $\begin{array}{l}\text { 2. Duration } \\
\text { unemployment(months) }\end{array}$ & & & & $13.11(5.69)$ & $0.13^{*}$ \\
\hline \multirow[t]{6}{*}{ 3. Coping strategy } & Problem-solving & & & $-63.98(15.97)$ & $-0.27^{* * *}$ \\
\hline & Self-blaming & & & $74.72(13.39)$ & $0.45^{* * *}$ \\
\hline & Help-seeking & & & $24.89(13.45)$ & 0.10 \\
\hline & Fantasizing & & & $25.69(17.14)$ & 0.12 \\
\hline & Avoidance & & & $-7.57(18.30)$ & -0.03 \\
\hline & Rationalization & & & $-22.13(23.01)$ & -0.08 \\
\hline$\overline{R^{2}}$ & & 0.05 & 0.11 & 0.45 & \\
\hline Adjust $R^{2}$ & & 0.04 & 0.09 & 0.42 & \\
\hline $\bar{F}$ & & $2.93^{*}$ & $5.16^{* * *}$ & $14.42^{* * *}$ & \\
\hline$\overline{\Delta R^{2}}$ & & & 0.06 & 0.33 & \\
\hline$\overline{\Delta F}$ & & & $13.36^{* * *}$ & $19.75^{* * *}$ & \\
\hline
\end{tabular}

Note: ${ }^{*} p<0.05{ }^{* *} p<0.01{ }^{* * * *} p<0.001$.

${ }^{\mathrm{a}}$ standardized regression coefficients at each step. 
unemployment [26-28], but not with other research indicating that the job loss is the primary contributor and intensified most at the time it occurs, subsiding later [29].

There are possible explanations for why long-term unemployed migrant workers in Eastern China have more mental problems. As the existing literature has indicated, being without a job for a long period of time allows stress to accumulate, coping resources to be depleted, and anxiety and tension to mount due to unemployment benefits running out and savings being exhausted $[48,49]$. Thus, the financial detriment of job loss increases as unemployment duration extends $[10,26,27]$. As a result, individuals with longer unemployment duration in China did show lower levels of mental health. On the other hand, for those short-term unemployed migrant workers in Eastern China, their initial challenging experience of migrating from rural villages to urban cities have equipped them with important life lessons and basic survival skills. Thus, their subsequent daily experience of obtaining and losing jobs temporarily might not become the sole or largest stressor in their lives. They still have their dreams for their future and might even have savings left. As a result, short term unemployed migrant workers showed less mental problems that those long term ones.

\section{Mental health and coping strategy of unemployed migrant workers}

The most commonly used coping strategy for unemployed migrant workers is problem-solving, indicating that they, in the face of difficulty and pressure, would take some positive and mature coping strategies to coping with it. This result is consistent with some employed worker research [50,51], but inconsistent with other unemployed worker research indicating that problem-solving was less frequent used among unemployed subjects [52].

Self-blaming and help-seeking rank the least, which are congruent with the previous research into coping strategies used by migrant workers in China [21]. It is possible that individuals in the sample would attribute the cause of their unemployment to the poor leadership of their unit and the inevitable result of the enterprise bankrupt during the economic crisis, and consider it little to do with individual abilities and qualities. Interestingly, findings from this study indicate that unemployed migrant workers use the coping strategy of help-seeking less. Unemployed migrants felt they needed help when they were depressed or anxious more than either urban or rural counterparts [21]. However, they were least likely to actually take action to get help. Unemployed migrant workers are separated from their accustomed support network, such as family or friends in the rural areas. Meanwhile, it is impossible for them to get the help from professional counselling and psychological support services due to its limitation and costliness in China [53].

With regards to the relationship between mental health status and the coping strategies utilized by unemployed migrant workers, mature coping strategy (e.g. problemsolving) and mixed coping strategy (e.g. rationalization) showed significant negative correlation with all the factors of SCL-90-R. In contrast, immature coping strategy (e.g. self-blaming, fantasizing) showed significant positive correlation with the factors. This finding is consistent with previous coping studies [54-56]. According to the research of Lazarus and Folkman, individuals with mature coping strategy could make direct efforts to alter or manage the source of the problem, which resulted in reducing anxiety and improving mental health [44]. In contrast, immature coping strategies are associated with psychological distress [57], high level of depression [58,59] and negative affect [60-62]. Although immature coping strategies can temporarily be used to escape the threat of pressure, yet the pressures are still there and have to be faced sooner or later, so they will lower the level of mental health. Comparison of SCL-90-R scores for different types of coping strategy also indicate that those who usually adopted mature type had comparatively good mental health; those who commonly used immature type had poor mental health; and those who were most likely to use mixed type between the above two types (mature and immature) were moderately mentally healthy.

\section{Hierarchical regression analysis for predicting GSI}

The regression analysis further revealed that duration of unemployment and two kinds of coping strategies (problem-solving and self-blaming) were the primary predictors of the mental health of unemployed migrant workers in our study. This finding might have practical implications. To prevent and address mental problems among unemployed migrant workers in China, for example, study on predicted factors may help policymakers develop programs to reduce the length time of unemployment and teach them how to increase the use of the problem-solving strategies and decrease the use of the self-blaming strategies.

\section{Conclusions}

This study indicates the mental problem of unemployed migrant workers was much more serious and widespread in Eastern China during the economic crisis. Duration of unemployment and two coping strategies, problemsolving and self-blaming are significant factors influencing their mental health. Given the massive number of unemployed migrants in China, their mental health should receive more attention. Despite limited resources, mental health could be improved through not only health 
care services but also social reforms. It is time for policymakers to develop new initiatives and to consolidate the existing policies that have been implemented in order to protect the mental health of the millions of unemployment migrant workers in China. It is important to note that the present study, using the cross-sectional design, has confirmed that unemployment and poor mental health are significantly related in one direction: unemployment may worsen mental health. However, the relationship could also work in reverse directions: mental health problems, particularly the common mental disorders such as anxiety and depression, may make it more difficult for a person to obtain and/or hold a job. Therefore, the reverse causal direction should be further examined in the future longitudinal studies.

\section{Abbreviations}

CSQ: Coping Styles Questionnaire; SCL-90-R: Symptom Check List 90; SOM: Somatization; O-C: Obsessive-Compulsive; I-S: Interpersonal Sensitivity: DEP: Depression; ANX: Anxiety; HOS: Hostility; PHOB: Phobic Anxiety; PAR: Paranoid Ideation; PSY: Psychoticism; GSI: Global Severity Index.

\section{Competing interests}

The authors declare that they have no competing interests.

\section{Authors' contributions}

$\mathrm{CL}$ designed the study, conducted the data analysis, and completed the first draft of this article. WJT participated in study design and coordination. LHW, WHL and JCH participated in the design of the study, and revised the manuscript. YZ made valuable suggestions on scholarly writing. All authors have read and approved the final manuscript.

\section{Acknowledgements}

L.C.is supported by grant Wyk11113 from Wenzhou culture research project and grant 12XKGJ27 from Zhejiang philosophy and social science planning project. We thank Dr. Minghua Zhen for his constructive comments during the review process. We especially thank Wenzhou Medical College undergraduates and postgraduates who helped with data collection and data entry.

\section{Author details}

'Department of Psychology, School of Environmental Science and Public Health, Wenzhou Medical College, Wenzhou, China. ${ }^{2}$ School of Psychology, Jiangxi Normal University, Nanchang, China. ${ }^{3}$ Department of Educational and Counseling Psychology, School of Education, The University at Albany, State University of New York, Albany, New York, USA.

Received: 13 March 2012 Accepted: 25 July 2012

Published: 2 August 2012

\section{References}

1. Hintikka J, Lehto SM, Niskanen L, et al: Unemployment and ill health: a connection through inflammation? BMC Public Health 2009, 9:410.

2. Janlert U: Economic crisis, unemployment and public health. Scand J Public Health 2009, 37(8):783-784.

3. Bartley M, Sacker A, Clarke P: Employment status, employment conditions, and limiting illness: prospective evidence from the British household panel survey 1991-2001. J Epidemiol Community Health 2004, 58(6):501-506.

4. Bartley M: Unemployment and ill health: understanding the relationship. J Epidemiol Community Health 1994, 48(4):333-337.

5. Wilson SH, Walker GM: Unemployment and health: a review. Public Health 1993, 107(3):153-162.

6. McKee-Ryan F, Song Z, Wanberg CR, Kinicki AJ: Psychological and physical well-being during unemployment: a meta-analytic study. J Appl Psychol 2005, 90(1):53-76.
7. Butterworth P, Leach LS, Pirkis J, Kelaher M: Poor mental health influences risk and duration of unemployment: a prospective study. Soc Psychiatry Psychiatr Epidemiol 2012, 47(6):1013-1021.

8. Madianos M, Economou M, Alexiou T, Stefanis C: Depression and economic hardship across Greece in 2008 and 2009: two cross-sectional surveys nationwide. Soc Psychiatry Psychiatr Epidemiol 2011, 46(10):943-952.

9. Liwowsky I, Kramer D, Mergl R, et al: Screening for depression in the older long-term unemployed. Soc Psychiatry Psychiatr Epidemiol 2009, 44(8):622-627.

10. Classen TJ, Dunn RA: The effect of job loss and unemployment duration on suicide risk in the United States: a new look using mass-layoffs and unemployment duration. Health Econ 2012, 21(3):338-350.

11. Comino EJ, Harris E, Silove D, Manicavasagar V, Harris MF: Prevalence, detection and management of anxiety and depressive symptoms in unemployed patients attending general practitioners. Aust N Z J Psychiatry 2000, 34(1):107-113.

12. Buerhaus PI, Auerbach DI: The recession's effect on hospital registered nurse employment growth. Nurs Econ 2011, 29(4):163-167.

13. Mantler J, Matejicek A, Matheson K, Anisman H: Coping with employment uncertainty: a comparison of employed and unemployed workers. J Occup Health Psychol 2005, 10(3):200-209.

14. Leino-Loison K, Gien LT, Katajisto J, Valimaki M: Sense of coherence among unemployed nurses. J Adv Nurs 2004, 48(4):413-422.

15. Binitie A: Mental health implications of economic growth in developing countries. Ment Health Soc 1976, 3(5-6):272-285.

16. Cooper B: Economic recession and mental health: an overview. Neuropsychiatr 2011, 25(3):113-117.

17. Mirowsky J, Ross CE: Age and the effect of economic hardship on depression. J Health Soc Behav 2001, 42(2):132-150.

18. Levecque K, Van Rossem R, De Boyser K, Van de Velde S, Bracke P. Economic hardship and depression across the life course: the impact of welfare state regimes. J Health Soc Behav 2011, 52(2):262-276.

19. Butterworth $P$, Rodgers B, Windsor TD: Financial hardship, socio-economic position and depression: results from the PATH Through Life Survey. SoC Sci Med 2009, 69(2):229-237.

20. Lee S, Guo WJ, Tsang A, et al: Evidence for the 2008 economic crisis exacerbating depression in Hong Kong. J Affect Disord 2010, 126(1-2):125-133.

21. Li L, Wang HM, Ye XJ, et al: The mental health status of Chinese rural-urban migrant workers: comparison with permanent urban and rural dwellers. Soc Psychiatry Psychiatr Epidemiol 2007, 42(9):716-722.

22. Cai F, Chan KW: The global economic crisis and unemployment in China. Eurasian Geography and Economics 2009, 50(5):513-553.

23. Wong DF, He X, Leung G, Lau Y, Chang Y: Mental health of migrant workers in China: prevalence and correlates. Soc Psychiatry Psychiatr Epidemiol 2008, 43(6):483-489.

24. Wong DF, Leung $\mathrm{G}$ : The functions of social support in the mental health of male and female migrant workers in China. Health Soc Work 2008, 33(4):275-285

25. Tang J, Gao X, Yu Y, Ahmed NI, Zhu H, Wang J, et al: Sexual Knowledge, attitudes and behaviors among unmarried migrant female workers in China: a comparative analysis. BMC Public Health 2011, 11:917.

26. Stankunas M, Kalediene R, Starkuviene S, Kapustinskiene V: Duration of unemployment and depression: a cross-sectional survey in Lithuania. BMC Public Health 2006, 6:174.

27. Mossakowski KN: The influence of past unemployment duration on symptoms of depression among young women and men in the United States. Am J Public Health 2009, 99(6):1826-1832.

28. Viinamaki H, Koskela K, Niskanen L, Arnkill R, Tikkanen J: Unemployment and mental wellbeing: a factory closure study in Finland. Acta Psychiatr Scand 1993, 88(6):429-433.

29. Nandi A, Galea S, Tracy M, et al: Job loss, unemployment, work stress, job satisfaction, and the persistence of posttraumatic stress disorder one year after the September 11 attacks. J Occup Environ Med 2004, 46(10):1057-1064.

30. Zubin J, Spring B: Vulnerability: a new view on schizophrenia. J Abnorm Psychol 1977, 86(2):103-126.

31. Nuechterlein KH, Dawson ME: A heuristic vulnerability/stress model of schizophrenic episodes. Schizophr Bull 1984, 10(2):300-312.

32. Taylor SE, Stanton AL: Coping resources, coping processes, and mental health. Annu Rev Clin Psychol 2007, 3:377-401. 
33. Silber E, Hamburg D, Coelho G, et al: Adaptive behavior in competent adolescents: Coping with the anticipation of college. Arch Gen Psychiatry 1961, 5:354-365

34. Lamberg T, Virtanen P, Vahtera J, Luukkaala T, Koskenvuo M Unemployment, depressiveness and disability retirement: a follow-up study of the Finnish HeSSup population sample. Soc Psychiatry Psychiatr Epidemiol 2010, 45(12):259-264.

35. Gubrium JF, Holstein JA: Handbook of Interview Research: Context and Method. Thousand Oaks,CA: Sage; 2002:537-556.

36. Crippa JA, de Lima OF, Del-Ben CM, et al: Comparability between telephone and face-to-face structured clinical interview for DSM-IV in assessing social anxiety disorder. Perspect Psychiatr Care 2008, 44(4):241-247.

37. Lee $S$, Tsang A, Lau $L$, et al: Concordance between telephone survey classification and face-to-face structured clinical interview in the diagnosis of generalized anxiety disorder in Hong Kong. J Anxiety Disord 2008, 22:1403-1411.

38. Han W, Xu L, Muhuang Z, et al: Study on the unemployment insurance for migrant workers. China Soft Science 2010, 8:37-45.

39. Shi R: Health Statistics and epidemiology practice course. 1st edition. Shanghai: Fudan press; 2008

40. Wang ZY: Symptom check list 90(SCL-90). Shanghai Jingshen Yixue 1984, 22(2):68-70.

41. Derogatis LR, Yevzeroff $H$, Wittelsberger B: Social class, psychological disorder, and the nature of the psychopathologic indicator. J Consult Clin Psychol 1975, 43(2):183-191.

42. Tong HJ: A research of twenty years' vicissitude: SCL-90 and its norm. Psychol Sci 2010, 33:928-930.

43. Xiao $J H, X u X F$ : The research of reliability and validity of the "Coping Style Questionnaire". China Mental Health 1996, 10:164-168.

44. Folkman S, Lazarus RS: An analysis of coping in a middle-aged community sample. J Health Soc Behav 1980, 21(3):219-239.

45. Chen SL, Li LJ: Re-testing reliability, validity and norm applicability of SCL-90. Chin J Nerv Ment Dis 2003, 29(5):323-327.

46. Liao CJ, Mao HP, Gong BH: Research on Mental health of migrant farmers in cities: an example of Wenzhou, Zhejiang. Ecol Econ 2010, 224(5):183-184.

47. Hwang SS, Xi J, Cao Y, Feng X, Qiao X: Anticipation of migration and psychological stress and the Three Gorges Dam project, China. Soc Sci Med 2007, 65(5):1012-1024.

48. Jackson PR, Warr PB: Unemployment and psychological ill-health: the moderating role of duration and age. Psychol Med 1984, 14(3):605-614

49. Prussia GE, Fugate M, Kinicki AJ: Explication of the coping goal construct: implications for coping and reemployment. J Appl Psychol 2001, 86(6):1179-1190.

50. Anderson DG: Coping strategies and burnout among veteran child protection workers. Child Abuse Negl 2000, 24(6):839-848.

51. Lemaire JB, Wallace JE: Not all coping strategies are created equal: a mixed methods study exploring physicians' self reported coping strategies. BMC Health Serv Res 2010, 10:208.

52. Grossi G: Coping and emotional distress in a sample of Swedish unemployed. Scand J Psychol 1999, 40(3):157-165.

53. Yan HQ: New challenges of psychiatry: the development of mental health service in Shanghai. Psychiatry Clin Neurosci 1998, 52:S357-S358.

54. Smari J, Arason E, Hafsteinsson H, Ingimarsson S: Unemployment, coping and psychological distress. Scand J Psychol 1997, 38(2):151-156.

55. Hamilton VL, Hoffman WS, Broman CL, Rauma D: Unemployment, distress, and coping: a panel study of autoworkers. J Pers Soc Psychol 1993, 65(2):234-247.

56. Starrin B, Larsson G: Coping with unemployment-a contribution to the understanding of women's unemployment. Soc Sci Med 1987, 25(2):163-171.

57. Cohen L, Fouladi RT, Katz J: Preoperative coping strategies and distress predict postoperative pain and morphine consumption in women undergoing abdominal gynecologic surgery. J Psychosom Res 2005, 58(2):201-209.

58. Goodwin RD: Association between coping with anger and feelings of depression among youths. Am J Public Health 2006, 96(4):664-669.

59. Tobin DL, Griffing AS: Coping and depression in bulimia nervosa. Int J Eat Disord 1995, 18(4):359-363.
60. Billings DW, Folkman S, Acree M, Moskowitz JT: Coping and physical health during caregiving: the roles of positive and negative affect. $J$ Pers Soc Psychol 2000, 79(1):131-142

61. Castellani B, Wootton E, Rugle L, et al: Homelessness, negative affect, and coping among veterans with gambling problems who misused substances. Psychiatr Serv 1996, 47(3):298-299.

62. Spoor ST, Bekker MH, Van Strien T, et al: Relations between negative affect, coping, and emotional eating. Appetite 2007, 48(3):368-376.

doi:10.1186/1471-2458-12-597

Cite this article as: Chen et al:: Mental health, duration of unemployment, and coping strategy: a cross-sectional study of unemployed migrant workers in eastern china during the economic crisis. BMC Public Health 2012 12:597.

\section{Submit your next manuscript to BioMed Central and take full advantage of:}

- Convenient online submission

- Thorough peer review

- No space constraints or color figure charges

- Immediate publication on acceptance

- Inclusion in PubMed, CAS, Scopus and Google Scholar

- Research which is freely available for redistribution 